\title{
Ion Beam Sputtering Monitored by Optical Spectroscopy
}

\author{
M. Ait El FQIH ${ }^{a, b, *}$ AND P.-G. Fournier ${ }^{a}$ \\ ${ }^{a}$ Laboratoire de Spectroscopie de Translation des Interactions Moléculaires \\ Université Paris-Sud, Bât. 478, 91405 Orsay, France \\ ${ }^{b}$ Equipe SIAM - Département de Physique, Université Cadi Ayyad, Faculté des Sciences Semlalia \\ B.P. 2390, Marrakech, Maroc
}

(Received May 19, 2008; revised version November 23, 2008)

\begin{abstract}
Optical spectroscopy gives a simple means to follow the evolution of the surface composition during ion beam sputtering. This is illustrated by three examples: air oxidised metals $(\mathrm{Al}$ and $\mathrm{Cu}$ ), various $\mathrm{CuAl}$ alloys and the $\mathrm{Cu}_{98} \mathrm{Be}_{2}$ alloy. Several time scales are distinguished, corresponding to different processes: the elimination of surface contaminants, the removal of the corroded layer. The implications for the use of ion beam optical spectroscopy in surface analysis are discussed.
\end{abstract}

PACS numbers: 68.49.Sf, 79.20.Rf

\section{Introduction}

Ion beam sputtering is a means of probing the surface of a material for analytical purpose. Secondary ion mass spectroscopy (SIMS), which identifies the ejected particles by their mass, is the most sensitive technique. Optical spectroscopy [1-7], which uses the light emitted by excited particles, has other advantages. Identification by a set of atomic lines is devoided of ambiguity. The signal is less affected by space charge problems in the case of insulating targets. The technique is relatively cheap and easy to use. However, the alteration of the surface by the bombardment is a problem, especially if, for sensitivity reasons, a high ion current is used. The alteration is both geometrical and chemical. Geometrically, a microrelief grows during the bombardment if the impact zone and the direction of incidence are left unchanged, especially if the sample is polycrystalline. Chemically, the surface composition changes due to atomic displacements and differences in sputtering yields. This effect involves not only the species present in the bulk, but also surface contaminants.

The purpose of this paper is to evaluate some of these effects and discuss their implications for the use of ion beam optical spectroscopy in surface analysis. Three examples are considered: air oxidised metals, various $\mathrm{CuAl}$ alloys and the $\mathrm{Cu}_{98} \mathrm{Be}_{2}$ alloy.

\section{Experimental results}

The setup has been described previously [8-10]. $5 \mathrm{keV}$ $\mathrm{Kr}^{+}$ions form a beam of typical intensity $2 \mu \mathrm{A}$ and cross-section $1 \mathrm{~mm}^{2}$. The target is tiltable. Light is detected at right angle from the ion beam in the plane of incidence. The range of the spectrograph is $190-590 \mathrm{~nm}$.

* corresponding author; e-mail: m.aitelfqih@gmail.com
The detector is a photomultiplier, not a diode array, so the time evolution is obtained either by following the intensity of a given atomic line, or by carrying out partial or complete scans from time to time (a complete scan lasts approximately $15 \mathrm{~min}$ ).

The samples are prepared by mechanical polishing and ultrasonic cleaning in ethanol, then placed in ultrahigh vacuum $\left(10^{-9}\right.$ Torr $)$. The start of all the evolutions reported below is that of the bombardment. Unless otherwise specified, the angle of incidence is $70^{\circ}$ from the normal, which maximises the sputtering yield. The erosion velocity is then of the order of $1 \mathrm{~nm} / \mathrm{s}$.

\section{Results}

\subsection{Air oxidised metals}

Aluminium and copper samples were left in air for $1 \mathrm{~h}$ between their preparation and their installation in the vacuum chamber. The intensity of a given atomic line, $309.3 \mathrm{~nm}$ for $\mathrm{Al}$ and $324.8 \mathrm{~nm}$ for $\mathrm{Cu}$, was followed until the evolution is masked by noise. Figure 1 shows the results.

For aluminium, the maximum is reached $7 \mathrm{~s}$ after the start of the bombardment. At that time the adsorbed layers and most of the oxide layer have been eliminated and the signal is at a high level (about 4 times the final value) which evokes emission in the presence of oxygen. Then the signal diminishes rapidly and the difference from the final value tends to follow a power law $1 / t \gamma$ with $\gamma \approx 1.2$. Such a law with $\gamma$ a little more than unity is characteristic of a situation where one randomly collects items which are more and more difficult to collect as they become rarer [11]. The power law behaviour explains the difficulty of getting rid of the residual oxygen which the bombardment partly takes off and partly pushes into the target and which reacts with aluminium.

For copper, the general behaviour is the same, but the timescale is much shorter. After 2 min, the signal takes 


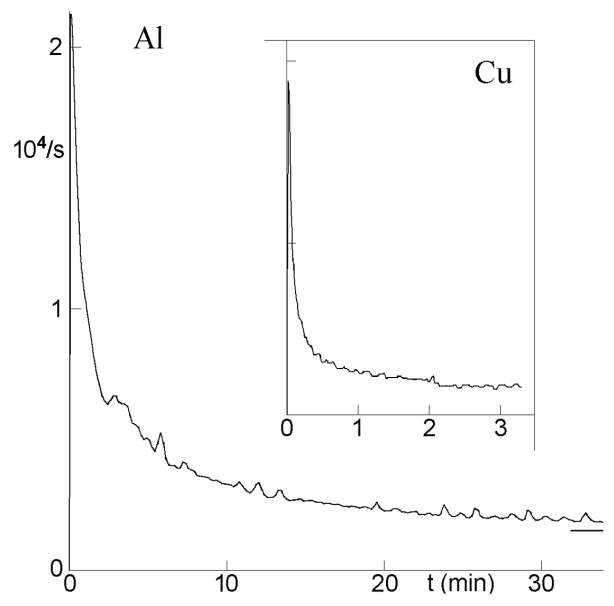

Fig. 1. Main graph: intensity of the $\mathrm{Al} 309.3 \mathrm{~nm}$ line during the bombardment of an aluminium target. The maximum is reached in $7 \mathrm{~s}$. The signal takes about $1 \mathrm{~h}$ to stabilise. The corresponding level is marked at right hand. Inset: intensity of the $\mathrm{Cu}(\mathrm{I})$ line at $324.8 \mathrm{~nm}$ during the bombardment of a copper target.

about $1 \mathrm{~h}$ to stabilise because the $\mathrm{Cu}$ simple is cleaned in situ by ion beam. It is well known that the emitted light strongly depends on the condition of the surface under ion bombardment and, therefore, from the basis of surface chemical analysis, where the species present at the surface can be identified by their characteristic line emission. In some cases, the light intensity is found to be strongly sensitive to the surface contamination (for example oxygen) [6].

\subsection{CuAl alloys}

$\mathrm{CuAl}$ alloys were produced by induction melting and solidification in situ. Samples were cut off from the solidified blocks by sawing. Three alloys were studied:

- The monophased alloy $\mathrm{Cu}_{4} \mathrm{Al}$ of mass composition $\mathrm{Cu}_{90.6} \mathrm{Al}_{9.4}$;

- The hypoeutectics $\mathrm{Cu}_{28.6} \mathrm{Al}_{71.4}$ and $\mathrm{Cu}_{21.6} \mathrm{Al}_{78.4}$.

A hypoeutectic is made of pure $\mathrm{Al}$ zones interdigitated with eutectic zones with a typical spacing of 10-100 $\mu \mathrm{m}$. The eutectic $\left(\mathrm{Cu}_{33} \mathrm{Al}_{67}\right)$ is made of alternate lamellae of $\mathrm{CuAl}_{2}$ and $\mathrm{Al}$ with a typical spacing of $1-10 \mu \mathrm{m}$. The samples are therefore not homogeneous, but the inhomogeneities are much smaller than the impact zone.

The observed atomic lines were $324.8 \mathrm{~nm}$ for $\mathrm{Cu}$ and $396.2 \mathrm{~nm}$ for Al. Their general evolution looks like that of the "pure" metals as described before (see Fig. 2a, $\mathrm{b}$, and $\mathrm{c}$ ). More interesting is the ratio of $\mathrm{Al}$ and $\mathrm{Cu}$ intensities, as shown in Fig. 3. Since the apparatus does not allow two atomic lines to be followed simultaneously, distinct impact points were used for the two intensities. Several scans were also carried out, until $4 \mathrm{~h}$ after the start of the bombardment.

For the monophased alloy, the intensity ratio is seen to be practically constant. The further scans did not show
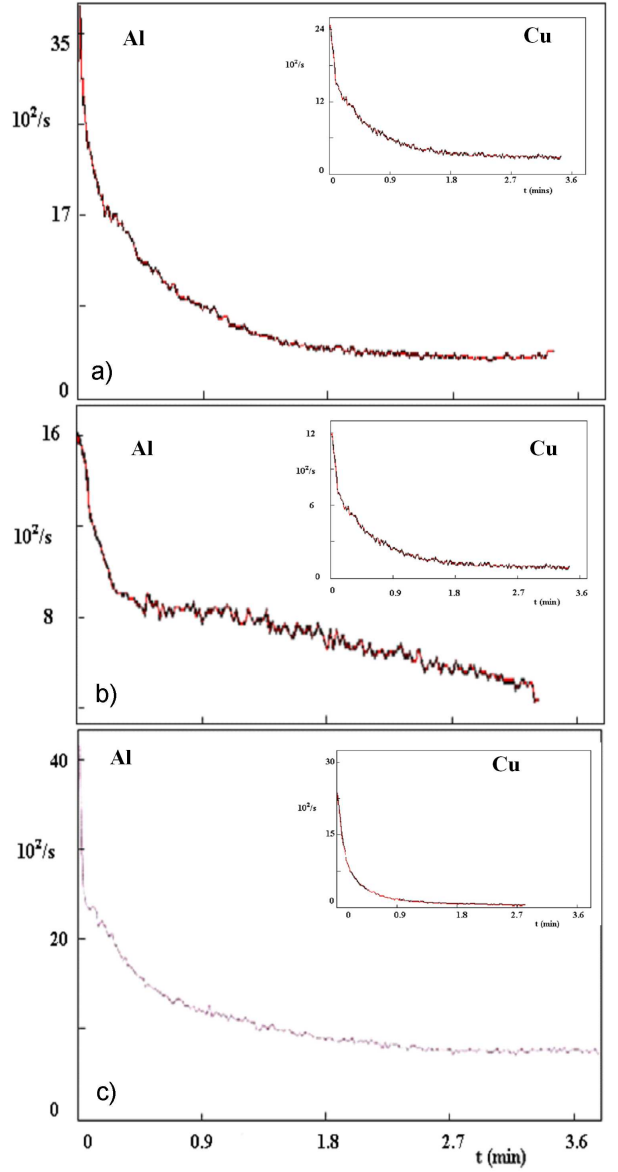

Fig. 2. (a) Main graph: intensity of the $\mathrm{Al} 309.3 \mathrm{~nm}$ line during the bombardment of $\mathrm{Cu}_{90.6} \mathrm{Al}_{9.4}$ target. Inset: intensity of the $\mathrm{Cu}(\mathrm{I})$ line at $324.8 \mathrm{~nm}$ during the bombardment of $\mathrm{Cu}_{90.6} \mathrm{Al}_{9.4}$ target. (b) Main graph: intensity of the $\mathrm{Al} 309.3 \mathrm{~nm}$ line during the bombardment of $\mathrm{Cu}_{28.6} \mathrm{Al}_{71.4}$ target. Inset: intensity of the $\mathrm{Cu}(\mathrm{I})$ line at $324.8 \mathrm{~nm}$ during the bombardment of $\mathrm{Cu}_{28.6} \mathrm{Al}_{71.4}$ target. (c) Main graph: intensity of the $\mathrm{Al} 309.3 \mathrm{~nm}$ line during the bombardment of $\mathrm{Cu}_{21.6} \mathrm{Al}_{78.4}$ target. Insert: intensity of the $\mathrm{Cu}(\mathrm{I})$ line at $324.8 \mathrm{~nm}$ during the bombardment of $\mathrm{Cu}_{21.6} \mathrm{Al}_{78.4}$ target.

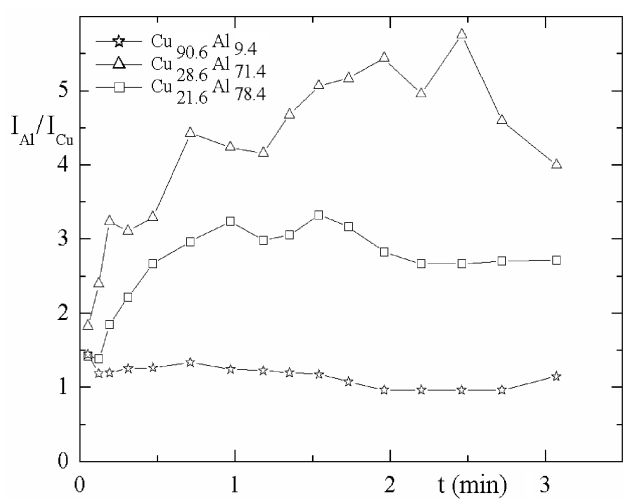

Fig. 3. Intensity ratio of the $\mathrm{Al} 396.2 \mathrm{~nm}$ and $\mathrm{Cu}$ $324.8 \mathrm{~nm}$ atomic lines during the first 3 minutes of the bombardment of various $\mathrm{CuAl}$ alloys. 
any significant change. This means that the proportion of ejected $\mathrm{Al}$ and $\mathrm{Cu}$ atoms is always the bulk one.

For the hypoeutectics, the initial intensity ratio is nearly the same as for the monophased alloy, whereas the number of $\mathrm{Al}$ atoms per $\mathrm{Cu}$ atom in the bulk is 24 or 34 times larger. Even after $3 \mathrm{~min}$, the intensity ratio does not exceed 3 or 5 , as shown in Fig. 3. Several hours are necessary to attain values of several tens as expected. The inhomogeneity of the samples and the use of two impact points can affect the results and does not explain a factor of 24 or 34 . It is clear that the initial surface is strongly deficient in aluminium. Whether it is due to the shaping of the samples, their preparation, oxygen diffusion or only the existence of the suface, is the subject of further investigations.

\section{3. $\mathrm{CuBe}$ alloy}

This case is chosen to illustrate long time effects in composition and morphology changes. The target is a $\mathrm{Cu}_{98} \mathrm{Be}_{2}$ alloy. The observed atomic lines are at $324.8 \mathrm{~nm}$ for $\mathrm{Cu}$ and $332.1 \mathrm{~nm}$ for Be. Figure 4 shows the ratio of their intensities at different times for beam incidences of $0^{\circ}$ and $70^{\circ}$ from the normal. This ratio is expected to

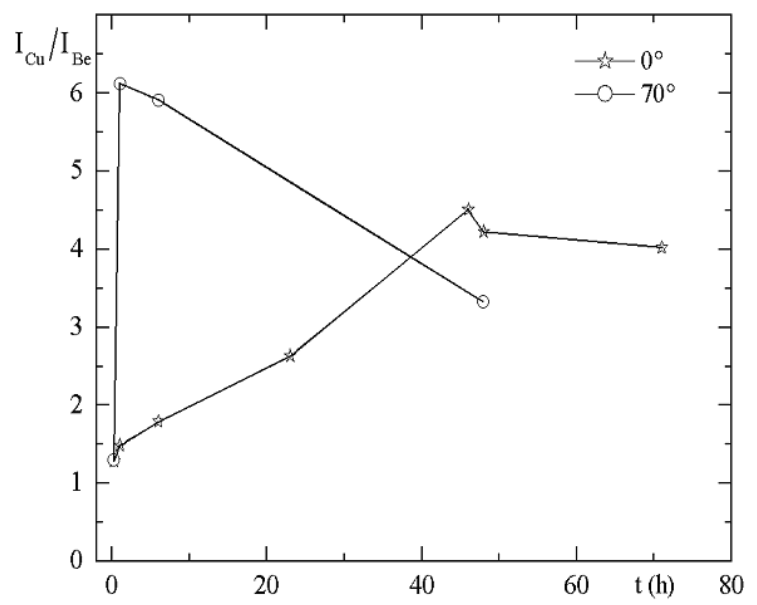

Fig. 4. Intensity ratio of the $\mathrm{Cu} 324.8 \mathrm{~nm}$ and $\mathrm{Be}$ $332.1 \mathrm{~nm}$ atomic lines during the bombardment of a $\mathrm{Cu}_{98} \mathrm{Be}_{2}$ alloy at different times (in hours) for two angles of incidence. The three first measurements are made $15 \mathrm{~min}, 1 \mathrm{~h}$ and $6 \mathrm{~h}$ after the start of the bombardment.

essentially depend on the ratio of the $\mathrm{Cu}$ and Be sputtering yields, even if some influence of the angle of incidence on the excitation probability cannot be excluded due to differences in the collision sequences. At large times, the ratio of the sputtering yields tends to the ratio of bulk atomic concentrations. The intensity ratios for different incidences are thus expected to converge. According to Fig. 1, this occurs after about $40 \mathrm{~h}$. The figure also shows convergence at relatively short times $(15 \mathrm{~min}$ after the start of the bombardment), but at a lower level, which would imply a preferential sputtering of beryllium if the surface had the bulk composition. Numerical simulations do not predict such a preferential sputtering (they rather predict preferential sputtering of copper) [12]. The initial surface is therefore enriched in beryllium. When the bombardment is at oblique incidence, the enriched layer is removed rapidly and the intensity ratio increases rapidly, too. When the incidence is normal, the process is much slower. However, the difference in the erosion velocities (a factor of 3 or 4 ) is not sufficient to explain the difference in the timescales. The surface undergoes morphological changes due to sputtering, with the formation of ripples, grooves and more complex structures [13-15]. The same mechanism which produces these structures produces composition variations along the surface. Micrographs of surface before and after bombardment will be taken in the future of this study to confirm these predictions. Whether it accelerates or slackens equilibration is an open question.

\section{Discussion and conclusion}

Ion beam optical spectroscopy is a tool to analyse the surface of a material locally. The analysis can become quantitative if calibration is carried out. However, the question of when the signal can be considered as representative of the sought for composition is posed.

When the bombardment begins, most of surface contaminants are eliminated. This gives a short transient signal which is easily identified. Reactive species, such as oxygen on aluminium, raise a more serious problem. Their influence on the signal is visible until a rather thick layer is eroded, of the order of $1 \mu \mathrm{m}$ in the Al case. Submicronic analysis is impossible if the problem is not circumvented. The solution is to bring oxygen in a controlled way, for instance by adding it to the ion beam, so that its surface concentration remains approximately constant.

When the target is inhomogeneous, the results may be difficult to interpret, especially if the successive steps in its elaboration have contributed to surface modifications. Erosion is not uniform, hollows are created and a steady state may be unattainable in the framework of a local analysis. To clarify the situation, complementary techniques such as optical or electron microscopies may be necessary.

When the bombardment is pursued for a long time, for instance for large depth profiling, a microrelief grows. The first and obvious consequence is that the location of the probed zone becomes uncertain. Furthermore, due to differences in the sputtering yields, composition changes accompany the morphology changes. The effect can be minimised by varying the direction of incidence during the bombardment.

This survey of some problems should not mask the advantages of ion beam optical spectroscopy. There are simple situations, such as profiling of successive homogeneous layers at the scale of some micrometres, where the technique does not raise any difficulty. Solutions exist for some more complicated situations, as discussed above. In conclusion, the technique is convenient and is worth developing. 


\section{References}

[1] C.W. White, Nucl. Instrum. Methods 149, 497 (1978).

[2] G.E. Thomas, Surf. Sci. 90, 381 (1979).

[3] E.W. Thomas, Vacuum 34, 1031 (1984).

[4] G. Betz, Nucl. Instrum. Methods Phys. Res. B 27, 104 (1987).

[5] M.L. Yu, Top. Appl. Phys. 64, 91 (1991).

[6] M. Suchanska, Prog. Surf. Sci. 54, 165 (1997).

[7] A. Cortona, W. Husinsky, G. Betz, Phys. Rev. B 59, 15495 (1999).

[8] J. Fournier, P.-G. Fournier, A. Kaddouri, H. Dunet, J. Appl. Phys. 69, 2382 (1991).

[9] P.-G. Fournier, J. Fournier, B. Bellaoui, O. Benoist d'Azy, G. Taieb, Nucl. Instrum. Methods Phys. Res. B 78, 144 (1993).
[10] O. Varenne, P.-G. Fournier, J. Fournier, B. Bellaoui, A. Faké, J. Rostas, G. Taieb, Nucl. Instrum. Methods Phys. Res. B 171, 259 (2000)

[11] P.-G. Fournier, A. Nourtier, M. Monkade, K. Berrada, H. Boughaleb, A. Outzourhit, R. Pichon, C. Haut, T. Govers, Compt. Rend. A. S., Phys. 7, 284 (2006).

[12] V.I. Shulga, private communication.

[13] R. Gago, L. Vázquez, R. Cuerno, M. Varela, C. Ballesteros, J.M. Albella, Appl. Phys. Lett. 78, 3316 (2001)

[14] P.-G. Fournier, A. Nourtier, V.I. Shulga, Phys. Chem. News 19, 60 (2004).

[15] P.-G. Fournier, A. Nourtier, V.I. Shulga, M. Ait El Fqih, Nucl. Instrum. Methods Phys. Res. B 230, 577 (2005) 